Mota, P., Machado, F., Biotto, C., Mota, R. and Mota, B. (2019). "BIM for Production: Benefits and Challenges for its Application in a Design-Bid-Build Project." In: Proc. $27^{\text {th }}$ Annual Conference of the International. Group for Lean Construction (IGLC), Pasquire C. and Hamzeh F.R. (ed.), Dublin, Ireland, pp. 687-698. DOI: https://doi.org/10.24928/2019/0243. Available at: <www.iglc.net>.

\title{
BIM FOR PRODUCTION: BENEFITS AND CHALLENGES FOR ITS APPLICATION IN A DESIGN-BID-BUILD PROJECT
}

\author{
Paula Mota ${ }^{1}$, Fernanda Machado ${ }^{2}$, Clarissa Biotto ${ }^{3}$, Ricardo Mota ${ }^{4}$, Bruno Mota $^{5}$
}

\section{ABSTRACT}

The poor management of the information flow in the AEC industry is a significant problem that might be overcome by the adoption of Building Information Modelling (BIM) and Lean Construction philosophy. Although the increasing use of BIM models by construction companies, the management of BIM models for production purposes still lacks a systematic investigation by scholars.

Thus, the paper presents a design-bid-build (D-B-B) project to investigate the necessary efforts of design and construction stakeholders in order to generate the BIM models for production. Moreover, the authors analysed the information flow, stakeholders' responsibilities and interactions in the BIM process.

The study finds that the effective use of BIM for production is impacted by the D-B-B route due to the lack of information for construction contained within the BIM models generated by designers. Likewise, the effort of modelling for production requires a new skilled professional with design and construction knowledge.

The study is limited to one case study outcomes; however, the constraints for the adoption of BIM for production are general to the AEC industry.

\section{KEYWORDS}

BIM, production, information flow, constructive model, design-bid-build, procurement.

\section{INTRODUCTION}

The management of the information flow in the AEC industry is a significant problem. Due to the inaccuracy, duplicity and inconsistency of building information, the stakeholders have to recollect information several times throughout the project life cycle, representing about 57\% of wasting effort (NIBS 2018). Building Information Modelling (BIM) may mitigate this problem.

\footnotetext{
MSc, BIM Manager, SIPPRO Consultancy, Fortaleza, Brazil, Paula.Mota@ sippro.eng.br

MSc, BIM Manager, Núcleo de Inovação BIM - NIB, Salvador, Brazil,

Fernanda.Machado@nucleobim.com

Post-Doc Researcher, Federal University of Sao Carlos, Brazil, Clerwice@ gmail.com

4 Civil Eng, CEO, SIPPRO Consultancy, Fortaleza, Brazil, Ricardo.Mota@ sippro.eng.br

5 Civil Eng., Lean Consultant, LogiKal, Birmingham, UK, Bmota@logikalprojects.com
} 
BIM is considered the current expression that best clarifies the digital innovation employed by the construction industry in recent decades (Succar and Kassem 2016). Its robustness facilitates the building information management, allowing an integrated flow and project delivery through the use of virtual models (Underwood and Isikdag 2011).

Due to BIM triggers the process and product innovation in organisations, previous studies have identified and demonstrated the synergy between BIM and Lean Construction (Ma et al. 2018; Oskouie et al. 2012; Sacks et al. 2010). Moreover, several authors have highlighted the potential benefits in implementing both initiatives (Dubler et al. 2010; Mandujano et al. 2015; Nascimento et al. 2018). This synergy has been explored by scholars since 2010 (Sacks et al. 2010), including BIM and Last Planner ${ }^{\text {TM }}$ System (Bhatla and Leite 2012; Tillmann and Sargent 2016; Toledo et al. 2016); BIM and IT solutions for construction management (Dave et al. 2011; Gurevich and Sacks 2014; Sacks et al. 2010), among other uses. In order to achieve a successful use of both Lean \& BIM, their processes must have compatible workflows (Sacks et al. 2018).

Despite the outstanding contributions and relevance of BIM to support the lean philosophy in the construction industry, it still lacks systematic discussions about the management of BIM models for production. Thus, it is necessary research on the design and construction interface to explore the influence of procurement routes, and stakeholders' responsibilities and interactions in the BIM process to guarantee a lean workflow. In this scenario, it is relevant to stress the importance of managing the design and construction data in the BIM models (Chen and Luo 2014), and to make additional modelling efforts to provide further consistency to the constructability analysis and to use in the production phase (Leite et al. 2011; Wang et al. 2016).

Therefore, this paper investigates a design-bid-build (D-B-B) project regarding the efforts and information flow among project participants in the design and construction interface in order to generate the BIM models for production purposes.

The authors used an exploratory literature review of the main foundations and studies about D-B-B procurement route, lean construction and BIM to support the descriptive case study (Yin 2003; Yin 2014) analysis. This research strategy allows an in-depth analysis of a real phenomenon inside an organisational context. Initially, the efforts of modelling were analysed the production uses. Secondly, a set of charts were generated based on the information flow among the stakeholders to examine the players who required, generated and modelled the information for production. Thirdly, the authors observed the project organisation and the D-B-B procurement route to find out the challenges for the successful implementation of BIM and lean in the project.

\section{LITERATURE REVIEW}

The New Product Development (NPD) process in the AEC industry comprehends the activities undertaken by companies to capturing the client's requirements and translating it into finished products. The NPD process includes a series of stages, for instance, design and construction. The procurement routes adopted in the construction projects affect the sequence and/or the degree of overlap between these phases.

The procurement routes establish contractual relationships between parties. The 
traditional route, such as Design-Bid-Build, has a single-stage tender, in which the design is completed before the construction starts. A consultant team develops the detail design for the client, and a contractor is appointed, usually under a lump-sum construction contract. In theory, it presents the least risky approach for the client, due to proper certainty about design, cost and duration (Morledge and Smith 2013). The contractor suffers penalties for late completion but has no responsibility for design. Hence, in this sort of procurement route, the full implementation of BIM throughout the AEC companies may be limited (Abd Jamil and Fathi 2018).

\section{LEAN \& BIM}

Lean construction does not necessarily need any technology to be implemented. However, some technological tools may support it, such as BIM tools (Sacks et al. 2018). Among the various BIM model uses (Succar et al. 2016), the interaction between Lean and BIM comprises: (a) constructability analysis of systems and subsystems (Gómez Cabrera et al. 2015); (b) physical-financial project scheduling (Sánchez-Rivera et al. 2017); (c) dynamic project control based on visualisation of the constructive process, through the integration of models to the Last Planner System (LPS) (Bhatla and Leite 2012); (d) production design, planning and control by means of 4D simulation tools (Biotto et al. 2015; Harris and Alves 2013); (e) production system management through the implementation of concepts such as KanBIM (Sacks et al. 2012), digital solutions such as VisiLean (Dave 2013), and a framework aligned with enabling technologies of Industry 4.0 (Dave et al. 2016), and; (f) communication platform for on-site teams, aiming to increase productivity in the field (Zhang et al. 2018) through BIM-stations (Vestermo et al. 2016 ) or BIM-kiosks (Bråthen and Moum 2016).

Although these different uses to support Lean, few BIM tools were explored to designing a production system before its operation. The use of BIM models is already supporting the production planning and control of on-site activities (Sacks et al. 2018). However, the content of the BIM models to attend the production is still unclear.

The production system design (PSD) is a managerial activity constantly neglected by the construction industry. It involves designing the production process to build a product through compatible technologies and resources (Biotto et al. 2017). It incurs a set of interdependent decisions related to the production organisation, and the study the best alternatives aligned with the project strategy (Schramm et al. 2004). The PSD should exist in concurrence with the product design stage, in order to integrate decisions about the building constructability and its production organisation (Biotto 2019).

\section{BUILDING INFORMATION MODELLING}

A BIM model is a rich representation of the building data, object-oriented, intelligent and parameterised, from which appropriate visions and data needs of multiple users can be extracted and analysed to generate information that can be used to make decisions and improve the delivery process of the building (AGC 2011). "There is a wide range of BIM applications in the construction industry, including constructability analysis, design verification and analysis of the product lifecycle (Leite et al. 2011); quantitative take-off, cost estimation, environmental comfort simulations, customer requirement modelling 
(Nisbet and Dinesen 2010); simulation of energy use, lighting, computational dynamics fluid and checking of building codes (GSA 2007)."

BIM pulls a technological and procedural change that tends to affect everyone involved in the construction industry (Succar et al., 2007 cited in Guillermo et al. (2009)). The implementation of BIM systems requires drastic changes in current business practices (Aouad and Arayici 2009).

According to Succar (2009), BIM has three stages of maturity, going from the Pre-BIM, passing through: 1) Object-based modelling; 2) Model-based collaboration; and 3) Network-based integration, and achieving the ultimate goal in the Integrated Project Delivery:

- Stage 1: Stakeholders deploy object-based 3D parametric software tools to generate sing-disciplinary models. Unsynchronised communication;

- Stage 2: Stakeholders collaborate and exchange information with other disciplinary players. Model-based collaboration may occur within one or between two stages of the product development: design-design stakeholders, or design-construction, etc. Unsynchronised communication. Requires some contractual arrangements;

- Stage 3: Integration and collaboration of stakeholders across the project lifecycle phases. Synchronised communication. complex analysis about constructability, operability and safety, and other $\mathrm{nD}$ modelling. Requires reconsiderations of contractual relationships, risk-allocation and workflows.

\section{PROJECT DESCRIPTION}

The study of this paper is the BS Design Corporate Towers, a commercial offices building located at Fortaleza, CE - Brazil. It is composed of 2 connected towers of 17 stores, plus 4 stores for public use and 5 basement floors for parking, totalising 10,000 sqm.

The design phase started in 2012, as a 2D CAD process. In 2014, the developer/owner hired a BIM manager company, called SIPPRO, to generate the 3D BIM models for clash detection, quantitative take-offs, structural analysis, studies of lighting, manufacturing precasted elements, and so on. In total, 18 disciplines were modelled.

Previously to the beginning of the construction phase in 2015, there was not any participation of the builder and contractors. They were engaged in the BIM process only during the construction phase, mainly to support the BIM modelling for production. In the latter, they provided detailed construction and assemblage information according to demands from the construction phase were emerging.

\section{STAKEHOLDERS' RELATIONSHIP}

The stakeholders' relationship during the design and construction phases occurred as the Traditional Design-Bid-Build Procurement Route. The owner contracted the main agents, such as designers, builders and the company responsible for the BIM Modelling - SIPPRO. The builder was in charge of hiring contractors, subcontractors and suppliers for the construction phase. In addition, the builder also had limited powers with all designers and SIPPRO. In this project, the design, tendering and construction phases were planned as sequential and linear processes. However, due to late critical design changes, the three 
phases suffered time extensions, overlapping each other. Figure 1 shows the comparison between the planned and actual D-B-B. The overlap was seen as an opportunity for builder and manufacturers require constructive detailing and information clarification from designers.

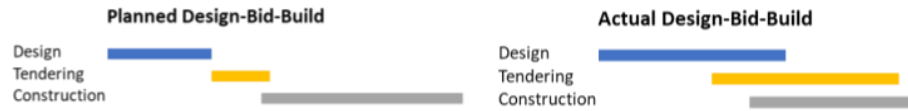

Figure 1: Planned and actual design, tendering and construction phases in the project.

\section{DEVELOPMENT}

The information flow between the design and construction phases is represented in Figure 2 , which includes the main modelling processes, related inputs and outputs. In the design phase, SIPPRO considered the Employer's Information Requirements (EIR) and defined the deliverables with the designers. The design team provided the $2 \mathrm{D}$ drawings as input to the initial development of BIM models, that lately was approved by the owner. It was an iterative modelling and discussions among all agents involved in the design phase.

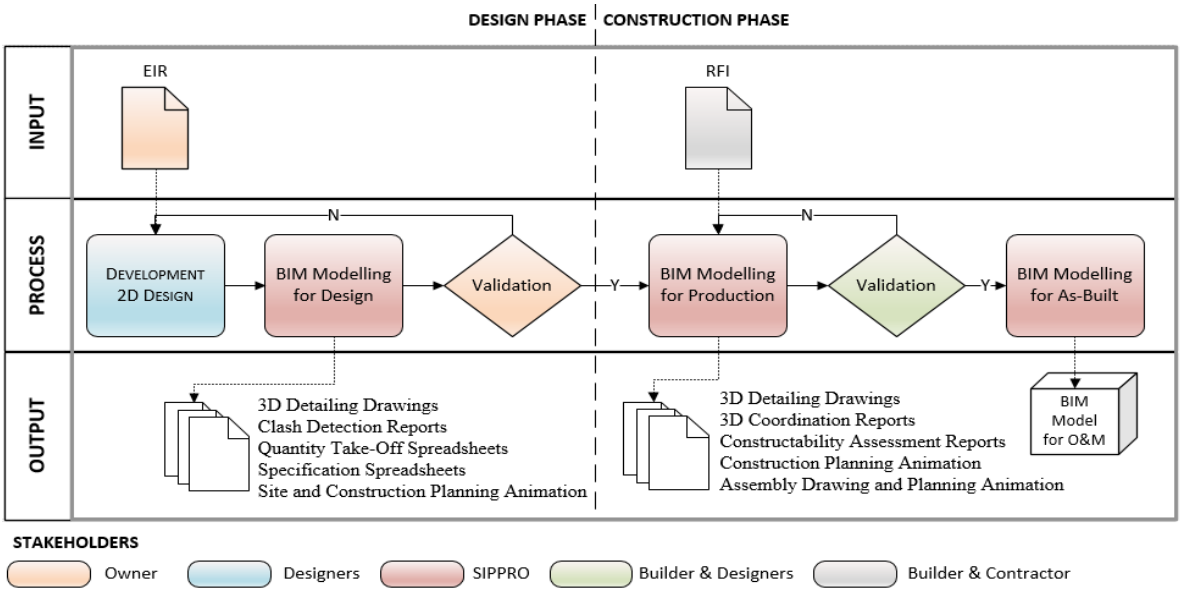

Figure 2: Information flow for BIM modelling process.

This article analyses data from 29 design solutions modelled by SIPPRO in the project during the design and construction processes. However, it is presented below 16 demands that had relation to the production, and intended to facilitate the PSD.

\section{DEMANDS FROM DESIGN}

The designers received 15 demands for new design information. It was necessary to increase the level of development of each building system, and create new BIM objects for simulation and analysis. In total, $66 \%$ of those fifteen model uses were directly related to production as detailed and illustrated below.

The model use for lean process analysis (Figure 3) supported the excavation and construction site planning, as well as served as a basis for defining the flow of soil excavated and grounded by the construction team. Another BIM functionality was the model use for spatial analysis (Figure 4) supported the optimisation of equipment 
positioning, which resulted in a significant cabling savings of $\mathrm{R} \$ 600,000$ (Brazilian currency). Moreover, the model use for selection and specification based on constructability analysis (Figure 5) comprised materials definition and requirements, i.e., new modelling efforts were necessary to analyse façade fixing, a situation not previously foreseen in the project. The model uses for visual communication, and clash detection (Figure 6) supported the identifying and reporting of design inconsistencies, enabling earlier collaboration and problem-solving among the stakeholders.

The model uses for both quantitative take-off, and construction planning (Figure 7) supported the project feasibility analysis, as well the cost estimation and monitoring during design and construction phases. The quantitative take-off reports aided the project schedule by the budgeting team. The model use for construction logistics (Figure 8) supported construction planning simulation for both construction site and building. The first case enabled the equipment positioning and reduced internal changes. The second case facilitated the steel structure assemblage planning, plus the equipment acquisition.
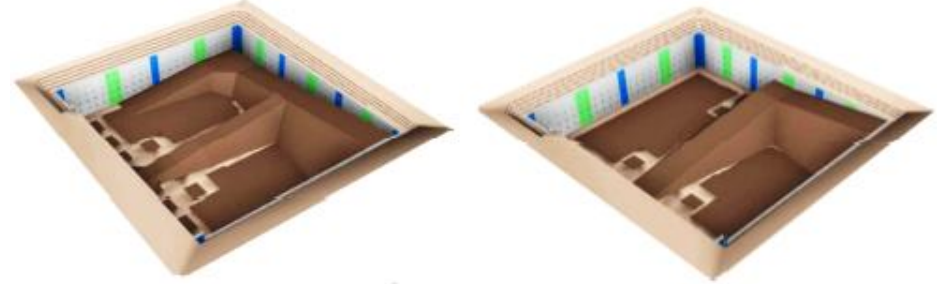

Figure 3: Model used for lean process analysis.
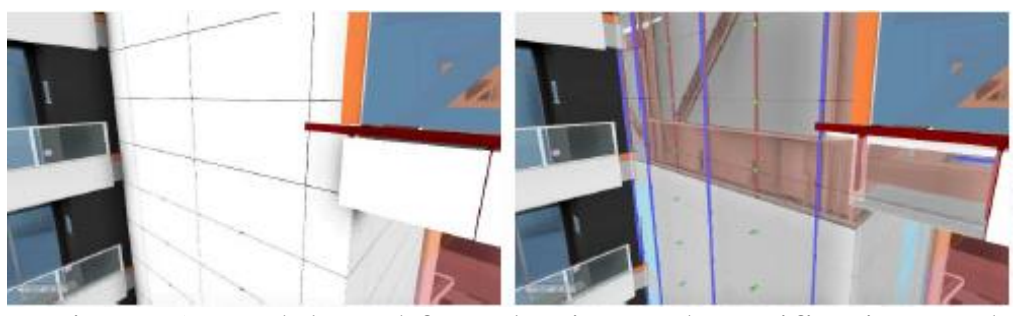

Figure 5: Model used for selection and specification, and constructability analysis.
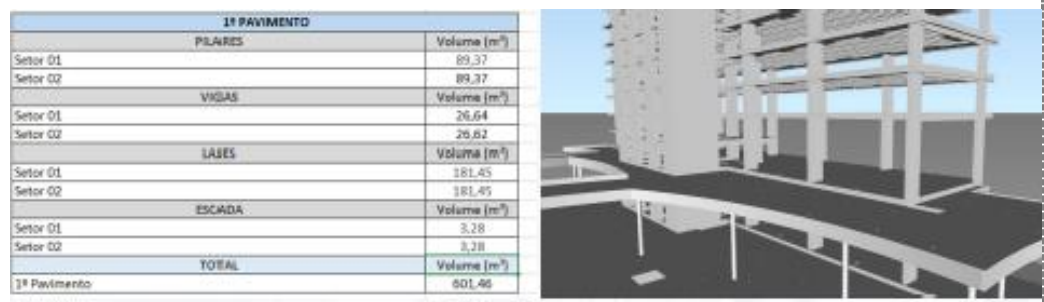

Figure 7: Model for quantity take-off, and construction planning.

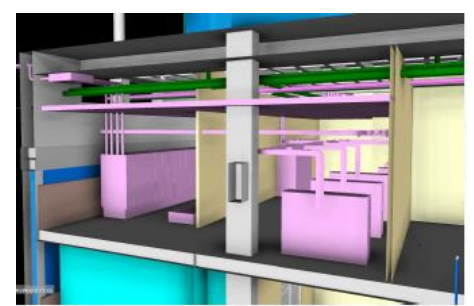

Figure 4: Spatial analysis.

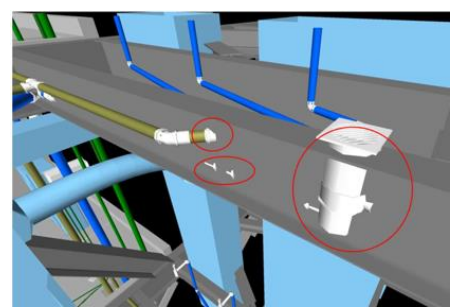

Figure 6: Visual communication, and clash.

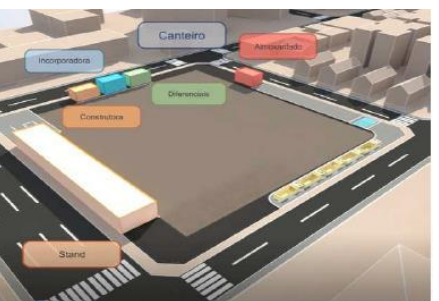

Figure 8: Construction logistics.

\section{DEMANDS FROM MANUFACTURING}

Validated models in the design phase were not detailed enough to meet the RFI specificities of the manufacturing phase. The demands for the pre-fabrication of steel beams, guard- 
rails, and cladding plates also reflected the increase of geometric and non-geometric data in the BIM models. Again, $66 \%$ of the model uses resulting from this phase were directly related to the production.

The model uses at this phase involved sheet steel forming and site set-out (Figure 9) both based on constructability analysis (Figure 10). In the first case, to coordinate the interface between steel structure and MEP/HVAC systems, SIPPRO provided more than 2800 mark-ups holes in the steel beams, saving $\mathrm{R} \$ 1,128,000$. since the execution of markups on the factory floor is free of charge. This practice facilitated both the stage of assemblage and the passage of installations on-site. Yet, in the second case, more than one solution was considered to enable the installation of $6 \mathrm{~km}$ of guard-rails. The chosen solution increased the productivity of the respective crew on the construction site.

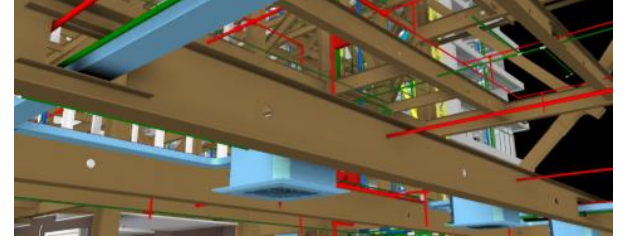

Figure 9: Model use for Sheet Metal Forming $\&$ Site Set-out.

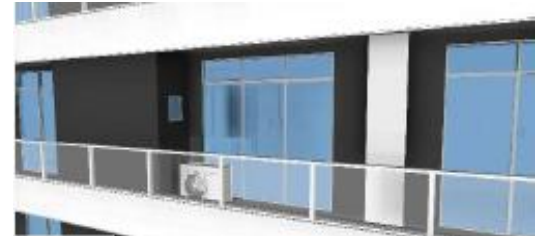

Figure 10: Model Use: Constructability Analysis.

\section{DEMANDS FROM CONSTRUCTION}

Finally, incremental changes were also required in the construction phase. The model uses that effectively aided production corresponded to 55\% of the RFI to SIPPRO. These uses ensured the quality, accuracy, and safety of the workforce.

The model use for constructability analysis (Figure 11 and Figure 12) supported the analysis of fixing the metal structure in the concrete structure through the application of chemical inserts. The model enabled a case-by-case analysis to generate execution templates preventing conflicts between the inserts and the reinforcement or pretension cables. This use involved the structural engineer in reviewing the position of each insert. Moreover, the model uses for quantity take-off (Figure 13) and structural analysis based on constructability analysis (Figure 14) included (i) the metallic inserts modelling necessary to assist the assembly of the transition beam of the concrete structure to the metallic structure; (ii) the modelling and quantifying of complementary metal-sheets in the U-beams, aiming the assembly of elevators; and (iii) the definition of the crane structure for lifting the main and transition metal beams, considering the simulation of equipment flow and the structural analysis of reinforcement.

The model use for field BIM (Figure 15) supported the production control through the slicing of BIM models for use in the construction site through mobile devices. Among the various application examples, we highlight the isolation of an HVAC model consisting of exhaustion, smoke extraction and stair pressurizing objects for on-site assembly monitoring of their pipeline and equipment.

The model use for construction planning (Figure 16) involved the 4D simulation and planning that supported demands that occurred during construction to verify and analyse the time and critical path of site activities. Considering that, the decision-making was 
assisted by the integration of BIM models to construction, assembly, and subcontractors' schedules.

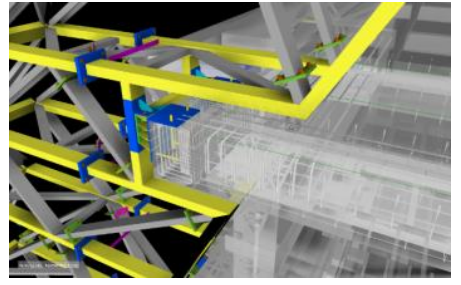

Figure 11: Constructability analysis.

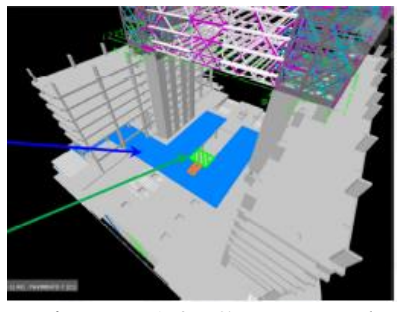

Figure 14: Structural analysis.

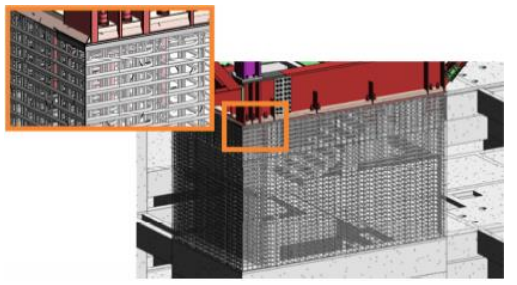

Figure 12: Constructability analysis.

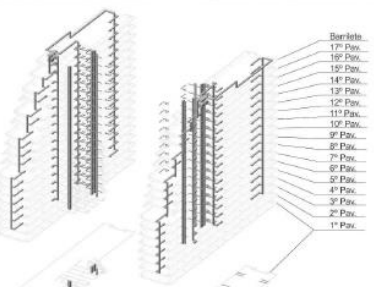

Figure 15: Field BIM.

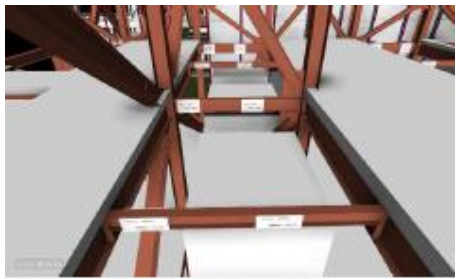

Figure 13: Quantity take-off \& constructability analysis.

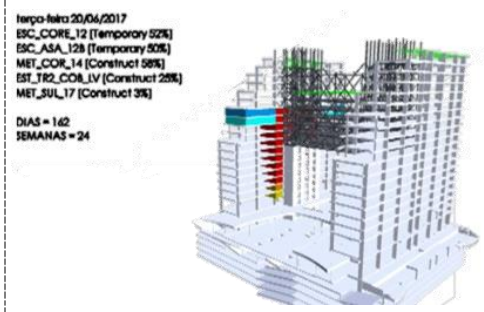

Figure 16: Construction planning.

\section{RESULTS ANALYSIS}

The data from 29 design solutions modelled by SIPPRO in the project was classified into seven categories: 1. If the solution was part of the design process, or if it was requested as extra information out of the design development; 2 . The nature of the solution: if it regarded the manufacturing, construction or design process; 3 . In which phase of the product development process the solution was generated: during design or construction; 4 . Who requested the development of the solution (builder, designers or SIPPRO); 5. Who generated the solution (builder, designers, SIPPRO or manufacturer); 6 . Who validated the solution (builder, designers, SIPPRO, manufacturer or developer); and, 7. If the effort to develop the solution was part of the contract between SIPPRO and the developer.

Figure 17 depicts that only $31 \%$ of the BIM modelling effort for design solutions was part of the design development process. It means that $69 \%$ of the requested solutions was beyond the design development. Figure 18, shows that almost half of the solutions generated concerned to design, $38 \%$ to construction and $10 \%$ to the manufacturing process of prefabricated elements. In Figure 19, the construction phase is the period when $90 \%$ of all solutions were generated.

Figure 20 depicts that, as a BIM model for production, $79 \%$ of solutions modelling were requested by the builder, whilst $17 \%$ by the designers, followed by $3 \%$ by SIPPRO. The next chart, Figure 21, presents outstanding data: the player responsible for generating and modeling the solutions was the consultancy company, SIPPRO, in $69 \%$ of the cases. It was the case of solutions for production, in which the designers did not detain the constructability knowledge.

Figure 22 shows that the validation of the solutions was performed by the builder and 
designers in $45 \%$ of the time for both, followed by the developer, SIPPRO and manufacturer.

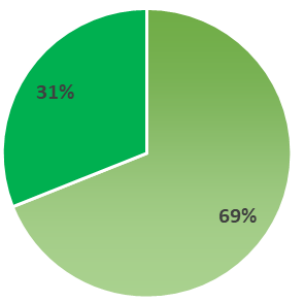

Figure 17: Solutions requested and developed out of the design phase.

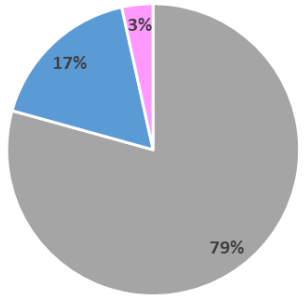

Figure 20: RFI requester.

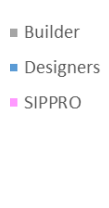

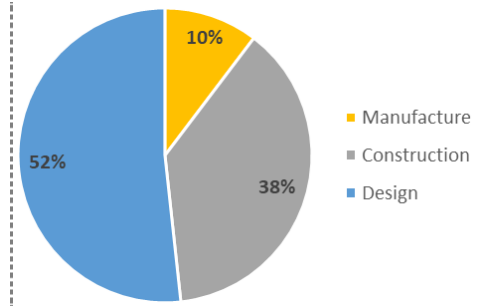

Figure 18: Nature of solutions: manufacture, construction or design origin. $3 \%$

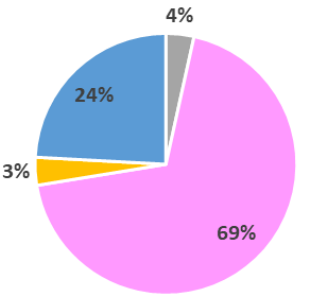

Figure 21: Solution developer.

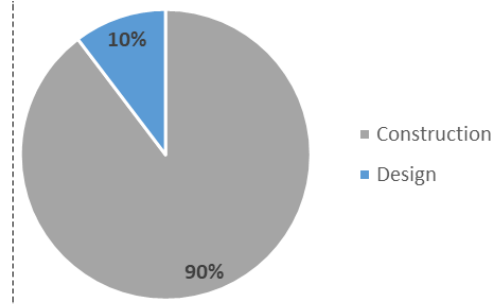

Figure 19: Phase when the solution was developed: design or construction.

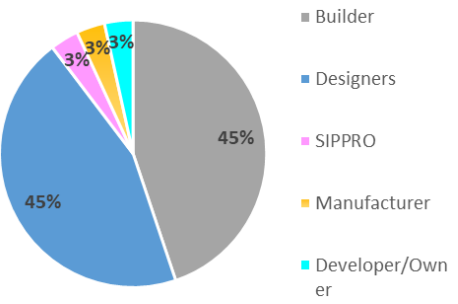

Figure 22: Solution validator.

Figure 23 illustrates one interesting fact: $41 \%$ of the design solutions were requested during the construction phase, despite the efforts to produce solutions during the design phase in order to have better designs ready for construction. Only $10 \%$ of the design solutions were developed during the design phase. As expected, $38 \%$ of construction solutions and $10 \%$ of manufacturing solutions were requested throughout the construction.

As the leading developer of design and construction solutions for the project, SIPPRO had many extra works, for instance, in Figure 24, $83 \%$ of all solutions were not in the scope accorded in the contract between SIPPRO and the Owner.

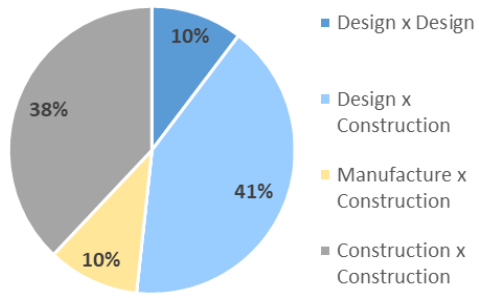

Figure 23: Crossing the nature of solution v.s. the phase it was requested.

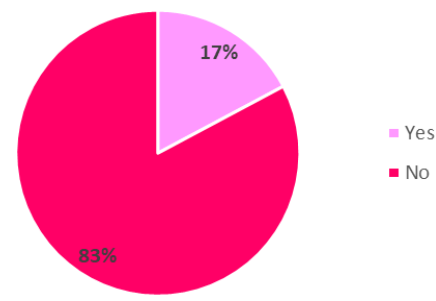

Figure 24: Solutions part of the SIPPRO's contract scope.

\section{CONCLUSIVE DISCUSSION}

This paper presented a descriptive case study of a D-B-B project which used BIM in the 
design and construction stages. From a total of 29 BIM modelling efforts, 16 were related to the be used for the PSD purpose. The model uses analysis showed that several demands from design, manufacturing and construction occurred due to the lack of detailed information in the drawings/models, which caused a high volume of design solutions been developed during the construction phase.

The set of charts generated based on the information flow among the stakeholders demonstrated that the main responsible for generating new design solutions for production was the consultant company SIPPRO. Thus, it is important to define a new skilled player to generate the BIM for production models, because SIPPRO's participation enhanced the production analysis which also created new design demands enabling gains and avoiding wastes during construction. These gains were extensive due to the early involvement of SIPPRO since the design phase. However, the gains could have been higher if the project adopted an EIR from the beginning of the design phase, planning the BIM deliverables and the players involved in construction demands.

Through the observation of the project organisation and the procurement route, the authors find out that the D-B-B was not the most suitable route for the successful development of constructive models. The D-B-B stimulates Stage 1 of BIM Maturity, although the project achieved Stage 2 (Succar, 2009). Other procurement routes that promote concurrent engineering should be adopted to implement BIM throughout the design and construction phases. Furthermore, the AEC industry needs to overcome contractual issues, i.e., to predict an early contractor involvement to design the production system aligned to the product design.

\section{REFERENCES}

Abd Jamil, A. H., and Fathi, M. S. (2018). "Contractual challenges for BIM-based construction projects: a systematic review." Built Environment Project and Asset Management, 8(4), 372385.

AGC (2011). "The Contractors' Guide to BIM.", Associated General Contractors of America.

Aouad, G., and Arayici, Y. (2009). Requirements Engineering for Computer Integrated Environments in Construction, Wiley-Blackwell, Oxford, UK.

Bhatla, A., and Leite, F. (2012). "Integration Framework of BIM with the Last Planner System." Proc., 20th Annual Conference of the International Group for Lean Construction, San Diego, USA.

Biotto, C. (2019). "Integration of overlapped design and construction stages through location-based planning tools." Doctorate, University of Huddersfield, Huddersfield.

Biotto, C., Kagioglou, M., Koskela, L., and Tzortzopoulos, P. (2017). "Comparing Production Design Activities and Location-Based Planning Tools." Proc., 25th Annual Conference of the International Group for Lean Construction, Heraklion, Greece, 705-712.

Biotto, C. N., Formoso, C. T., and Isatto, E. L. (2015). "Uso de modelagem 4D e Building Information Modeling na gestão de sistemas de produção em empreendimentos de construção." Ambiente Construído, 15(2), 79-96.

Bråthen, K., and Moum, A. (2016). "Bridging the gap: bringing BIM to construction workers." Engineering, Construction and Architectural Management, 23(6), 751-764.

Chen, L., and Luo, H. (2014). "A BIM-based construction quality management model and its applications." Automation in Construction, 46, 64-73. 
Dave, B., Boddy, S., and Koskela, L. (2011). "Visilean: Designing a production management system with lean and BIM." 477-487.

Dave, B., Kubler, S., Främling, K., and Koskela, L. (2016). "Opportunities for enhanced lean construction management using Internet of Things standards." Automation in Construction, 61, 86-97.

Dave, B. A. (2013). "Developing a construction management system based on lean construction and building information modelling." $\mathrm{PhD}$ thesis, University of Salford.

Dubler, C. R., Messner, J. I., and Anumba, C. J. (2010). "Using Lean Theory to Identify Waste Associated with Information Exchanges on a Building Project." Construction Research Congress 2010, 708-716.

Gómez Cabrera, A., Quintana Pulido, N., and Orlando Ávila Díaz, J. (2015). "Simulación de eventos discretos y líneas de balance, aplicadas al mejoramiento del proceso constructivo de la cimentación de un edificio." Ingeniería y Ciencia, 11, 157-175.

GSA (2007). "GSA Building Information Modeling Guide 01 - BIM Guide Overview."

Guillermo, A. M., John, C., Agustin, C., and Thomas, F. (2009). "Building information modelling demystified: does it make business sense to adopt BIM?" International Journal of Managing Projects in Business, 2(3), 419-434.

Gurevich, U., and Sacks, R. (2014). "Examination of the effects of a KanBIM production control system on subcontractors' task selections in interior works." Automation in Construction, 37, 81-87.

Harris, B., and Alves, T. d. C. L. (2013). "4D Building Information Modeling and Field Operations: An Exploratory Study." Proc., 21th Annual Conference of the International Group for Lean Construction, Fortaleza, Brazil, 811-820.

Leite, F., Akcamete, A., Akinci, B., Atasoy, G., and Kiziltas, S. (2011). "Analysis of modeling effort and impact of different levels of detail in building information models." Automation in Construction, 20(5), 601-609.

Ma, X., Chan, A. P. C., Wu, H., Xiong, F., and Dong, N. (2018). "Achieving leanness with BIMbased integrated data management in a built environment project." Construction Innovation, $18(4), 469-487$.

Mandujano, M. G., Alarcón, L. F., Kunz, J., and Mourgues, C. (2015). "Use of Virtual Design and Construction, and Its Inefficiencies, From a Lean Thinking Perspective." Proc., 23rd Annual Conference of the International Group for Lean Construction, Perth, Australia, 836-845.

Morledge, R., and Smith, A. (2013). Building Procurement, John Wiley \& Sons, Incorporated, Hoboken, UK.

Nascimento, D., Caiado, R., Tortorella, G., Ivson, P., and Meiriño, M. (2018). "Digital Obeya Room: exploring the synergies between BIM and lean for visual construction management." Innovative Infrastructure Solutions, 3(1), 19.

NIBS (2018). "Building Information Modeling (BIM)." <http://www.wbdg.org/buildinginformation-modeling-bim>. (02/02/2019).

Nisbet, N., and Dinesen, B. (2010). "Constructing the Business Case: Building Information Modelling." British Standards Institution, London.

Oskouie, P., Gerber, D. J., Alves, T., and Becerik-Gerber, B. (2012). "Extending the Interaction of Building Information modeling and lean construction." Proc., 20th Annual Conference of the International Group for Lean Construction, San Diego, USA.

Sacks, R., Barak, R., Belaciano, B., Gurevich, U., and Pika, E. (2012). "KanBIMWorkflow Management System:Prototype implementation and field testing." Lean Construction Journal 2013, 19-25. 
Sacks, R., Korb, S., and Barak, R. (2018). Building lean, building BIM : improving construction the Tidhar way, Routledge, London.

Sacks, R., Koskela, L., Dave, B. A., and Owen, R. (2010). "Interaction of Lean and Building Information Modeling in Construction." Journal of Construction Engineering and Management, 136(9), 968-980.

Sacks, R., Radosavljevic, M., and Barak, R. (2010). "Requirements for building information modeling based lean production management systems for construction." Automation in Construction, 19(5), 641-655.

Sánchez-Rivera, O. G., Galvis-Guerra, J. A., Porras-Díaz, H., Ardila-Chacón, Y. D., and MartínezMartínez, C. A. (2017). "BrIM 5D models and Lean Construction for planning work activities in reinforced concrete bridges." Revista Facultad de Ingeniería, 26, 39-50.

Schramm, F. K., Costa, D. B., and Formoso, C. T. (2004). "The Design of Production Systems for Low-Income Housing Projects." Proc., 12th Annual Conference of the International Group for Lean Construction.

Succar, B. (2009). "Building information modelling framework: A research and delivery foundation for industry stakeholders." Automation in Construction, 18(3), 357-375.

Succar, B., and Kassem, M. (2016). "Building information modelling: Point of adoption." Proc., CIB World Conference Proceedings.

Succar, B., Saleeb, N., and Sher, W. (2016). "Model uses: foundations for modular requirements clarification language." Australasian Universities Building Education (AUBEA2016).

Tillmann, P., and Sargent, Z. (2016). "Last Planner \& Bim Integration: Lessons From a Continuous Improvement Effort." Proc., 24th Annual Conference of the International Group for Lean Construction, Boston, USA.

Toledo, M., Olivares, K., and González, V. (2016). "Exploration of a Lean-Bim Planning Framework: A Last Planner System and Bim-Based Case Study." Proc., 24th Annual Conference of the International Group for Lean Construction, Boston, USA.

Underwood, J., and Isikdag, U. (2011). "Emerging technologies for BIM 2.0." Construction Innovation, 11(3), 252-258.

Vestermo, A., Murvold, V., Svalestuen, F., Lohne, J., and Lædre, O. (2016). "BIM-Stations: What It Is and How It Can Be Used to Implement Lean Principles." Proc., 24th Annual Conference of the International Group for Lean Construction, Boston, USA.

Wang, J., Wang, X., Shou, W., Chong, H.-Y., and Guo, J. (2016). "Building information modelingbased integration of MEP layout designs and constructability." Automation in Construction, 61, 134-146.

Yin, R. K. (2003). Applications of case study research, Sage Publications, Thousand Oaks;London;. Yin, R. K. (2014). Case study research: design and methods, SAGE, Los Angeles, California.

Zhang, X., Azhar, S., Nadeem, A., and Khalfan, M. (2018). "Using Building Information Modelling to achieve Lean principles by improving efficiency of work teams." International Journal of Construction Management, 18(4), 293-300. 